\title{
DESENVOLVIMENTO E IMPLANTAÇÃO DA NOVA ESTRUTURA CURRICULAR NA FACULDADE DE MEDICINA DE RIBEIRÃO PRETO: DIFICULDADES E AVANÇOS
}

\author{
DEVELOPMENT AND IMPLANTATION OF THE NEW CURRICULAR STRUCTURE IN THE SCHOOLOF \\ MEDICINE OF RIBEIRÃO PRETO: DIFFICULTIESANDADVANCES.
}

Wiliam A. Prado

Docente do Departamento de Farmacologia e Presidente da Comissão de Graduação da Faculdade de Medicina de Ribeirão Preto da Universidade de São Paulo.

Correspondência: Departamento de Farmacologia da Faculdade de Medicina de Ribeirão Preto - Av. Bandeirantes, 3900, Ribeirão Preto - SP, Brasil - CEP: 14049-900 - Fax (016)-633-2301. E-mail wadprado@fmrp.usp.br

PRADO WA. Desenvolvimento e implantação da nova estrutura curricular na Faculdade de Medicina de Ribeirão Preto Dificuldades e avanços. Medicina, Ribeirão Preto, 29: 373 382, out./dez 1996.

RESUMO: A Faculdade de Medicina de Ribeirão Preto, através de sua Comissão de Graduação, iniciou, em 1993, a implantação de estrutura curricular de um novo curso, denominado Curso de Ciências Médicas que, através de um único exame vestibular permite a graduação do aluno em Medicina e/ou em Ciências Biológicas-Modalidade Médica. Além desta flexibilização de sua terminalidade, o novo curso foi dividido em três fases: básica, clínica e internato, cada uma com dois anos de duração. As disciplinas tradicionais foram integradas em novas disciplinas ou articuladas no tempo, reduzindo a repetição desnecessária de conteúdo Novas disciplinas foram introduzidas visando o contato mais precoce do aluno com a Rede de Saúde e sua melhor formação ética e humanística $\mathrm{Na}$ fase clínica foram introduzidas novas disciplinas contendo tópicos de Semiologia Especializada Outros avanços da nova sistemática incluem a implantação de recursos para o auto aprendizado do estudante e a inclusão de disciplinas optativas nos três primeiros anos do curso permitindo maior contato do aluno com o docente em seu laboratório e aumento do numero de estudantes interessados em programa de iniciação científica Como principais dificuldades são identificadas a resistência dos docentes em reduzir o uso de aulas teóricas como instrumento de ensino a sobrecarga de informações e a com pleta ausência de mecanismos de incentivo às atividades de ensino de graduação.

UNITERMOS: Educação Médica. Faculdade de Medicina. Educação de Pré-Graduação em Medicina.

\section{INTRODUÇÃO}

Desde sua fundação, a Faculdade de Medicina de Ribeirão Preto da Universidade de São Paulo (FMRPUSP), freqüentemente, envida esforços no sentido de discutir e reavaliar a estrutura de seu curso de Medicina. A maioria das tentativas de se executar alteração efetiva dessa estrutura, no entanto, esbarrou na organização política da unidade, inicialmente dividida em cátedras e, posteriormente, em departamentos. Como observado na maioria das escolas médicas $^{1}$, a irrestrita autonomia concedida aos departamentos, em muitos casos, resultou conteúdo de disciplinas desvinculado da estrutura curricular e dos próprios objetivos institucionais. 
As pequenas alterações efetuadas ao longo do tempo, na estrutura curricular da FMRPUSP, basearam-se mais em objetivos políticos de poder, na estrutura interna da Faculdade do que no de vincular as alterações, visando melhor adequar o produto final às reais necessidades de saúde de grande parte da população. Dentre os argumentos favoráveis a essas pequenas alterações, levou-se sistematicamente em conta a premissa de que quanto maior a carga horária atribuída a um departamento, maior a justificativa para a ampliação de seu quadro docente e maior a sua representação nos colegiados na unidade.

Inicialmente centrada no catedrático, e, progressivamente, sendo deslocada para a centralização no docente, a estrutura curricular raramente evoluiu para uma sistemática que permitisse obter egressos com formação efetivamente ampla e adequada aos objetivos terminais da FMRPUSP. Em alguns casos extremos, a estrutura curricular permitiu a individualização do conteúdo até o limite do "curso de um único docente", dentro de urna mesma disciplina, caracterizando "feudos didáticos" ainda mais restritos que os patrocinados pelos departamentos. O tempo gasto na formação teórica do estudante tomou-se, então, progressivamente, excessivo, e o conteúdo repetitivo, em detrimento do tempo necessário ao seu aprimoramento em procedimentos, defeito em parte somente corrigível com a permanência do estudante em regime de residência.

\section{ESTRATÉGIAS INICIAIS}

A Comissão de Graduação (CG) da FMRPUSP, inicialmente criada corno órgão assessor da Diretoria para assuntos de ensino de graduação, fez diversas tentativas de correção da estrutura curricular. Sem poder estatutário para efetivá-las, tais tentativas foram, na maioria das vezes, vetadas pela Congregação da Unidade, quando não, obstruídas pela ação política de um departamento ou mesmo de um catedrático. A despeito dessas dificuldades, a CG conseguiu, no período de agosto de 1989 à novembro de 1990, efetuar levantamento de opiniões de coordenadores de disciplinas e de representantes do corpo discente de então, como estratégia para a análise e estabelecimento de propostas concretas de reformulação da estrutura curricular do curso de Medicina da FMRPUSP ${ }^{2,3}$. Esse levantamento permitiu as seguintes conclusões: a- Necessidade de flexibilizar a estrutura curricular, visando a criação de espaço para introdução de outras atividades, particularmente aquelas que favorecessem a formação humanística do estudante; b- Necessidade de ampliar o internato para um ano e meio ou dois anos e a introdução, no mesmo, de período para realização de estágio optativo;

c- Necessidade de proceder revisão do curso de Semiologia, integrando-o com as disciplinas de Psicologia e Psicologia Médica, e permitindo abordagem de tópicos de Semiologia Especializada;

d- Necessidade de fusão de disciplinas, com melhor racionalização da carga horária e evitando repetição desnecessária de conteúdo, favorecendo a integração interdisciplinar;

e- Criação de espaços curriculares para introdução de disciplinas novas e/ou optativas;

f- Substituição do vigente critério de pré-requisitos por outro mais abrangente.

Em paralelo a 80 vagas oferecidas para o curso de Medicina, a unidade também oferecia, desde 1965, 20 vagas para o Curso de Ciências Biológicas Modalidade Médica (CCBMM). Em 1991, o então notório decaimento do referido curso apontava para a necessidade de profundas alterações de sua estrutura, conforme conclusões de comissão criada para tratar do assunto, dentro dos estudos para o estabelecimento de Plano Diretor da FMRPUSP ${ }^{4}$.

Somente em 1991, tendo tal competência garantida pelos Estatutos da USP, promulgados em 1988, pode a CG iniciar o processo de reforma curricular, tomando as conclusões obtidas em 1990 como ponto de partida para a apresentação à Congregação da FMRPUSP de proposta de "Diretrizes gerais dos cursos de graduação na FMRPUSP", que estabelecia: a- Extinção do concurso vestibular para o CCBMM e o oferecimento de 100 vagas da unidade, através de um mesmo vestibular, para um curso novo: $\mathrm{Ci}$ ências Médicas, no qual o aluno poderá, em qual quer etapa, optar pelo bacharelato em Ciências Biológicas - Modalidade Médica (CBMM), Medicina, ou ambas, ou eventualmente completar programa de pós-graduação após a obtenção do bacharelato em CBMM, sem prejuízo de posterior graduação em Medicina;

b- Revisão dos conteúdos das disciplinas, buscando maior integração, fusão de disciplinas ou, ainda, inclusão de novas disciplinas;

c- Criação de espaços para a realização de estágios optativos;

d- Ampliação do período de internato;

e- Ampliação do ensino ao nível dos ambulatórios do Hospital das Clínicas da FMRPUSP, adequando a grade curricular ao funcionamento dos mesmos, e 
utilização didática dos ambulatórios das unidades primárias e secundúrias do Sistema Regional de Saúde, sob supervisão, conforme as peculiaridades das disciplinas:

f - Substituição do (então) atual esquema de pré-requisitos por outro mais abrangente.

O primeiro item das diretrizes foi aprovado pela Congregação da FMRPUSP em 26/07/1991 e implementado em $1993^{6}$. Os demais quesitos foram aprovados no mérito e a CG, finalmente, encarregada de oferecer proposta definitiva de nova estrutura curricular.

\section{ESTRATÉGIA PARA A REESTRUTURAÇÃO}

Como primeira fase desse processo, decidiu-se pela organização do Ciclo Básico que, dada a premissa de expansão do período de internato, deveria ter seu conteúdo desenvolvido em, no máximo, dois anos. O Ciclo Clínico, ocuparia dois anos e meio e o Internato seria desenvolvido em um ano e meio. Mais tarde, optou-se pela aprovação do Internato em dois anos, ficando o Curso Clínico, então, restrito ao período de dois anos ${ }^{7}$.

Como estratégia para nortear o processo de reestruturação do Ciclo Básico, foram convidados alguns docentes envolvidos com as disciplinas tradicionais para avaliarem a possibilidade de:

a- Integração de disciplinas afins e, na impossibilidade de imediata integração, articulá-las no tempo, de modo a viabilizar a integração de seus conteúdos, em outra oportunidade;

b- Estabelecer seqüência de disciplinas, segundo critério de complexidade crescente. Outros docentes foram sendo agregados ao grupo inicial, de modo a ampliar, gradativamente, o nível da discussão e a própria divulgação das intenções da CG, no encaminhamento do processo.

Estratégia similar foi utilizada com docentes do Ciclo Clínico. Foi possível, então, organizar, em um anteprojeto, as propostas emanadas dos diversos grupos de discussão (Figura 1), apresentado à comunidade docente e discente da FMRPUSP, no "Seminário sobre a estrutura curricular do curso de Ciências Médicas", realizado no período de 6 a 9 de abril de 1992.

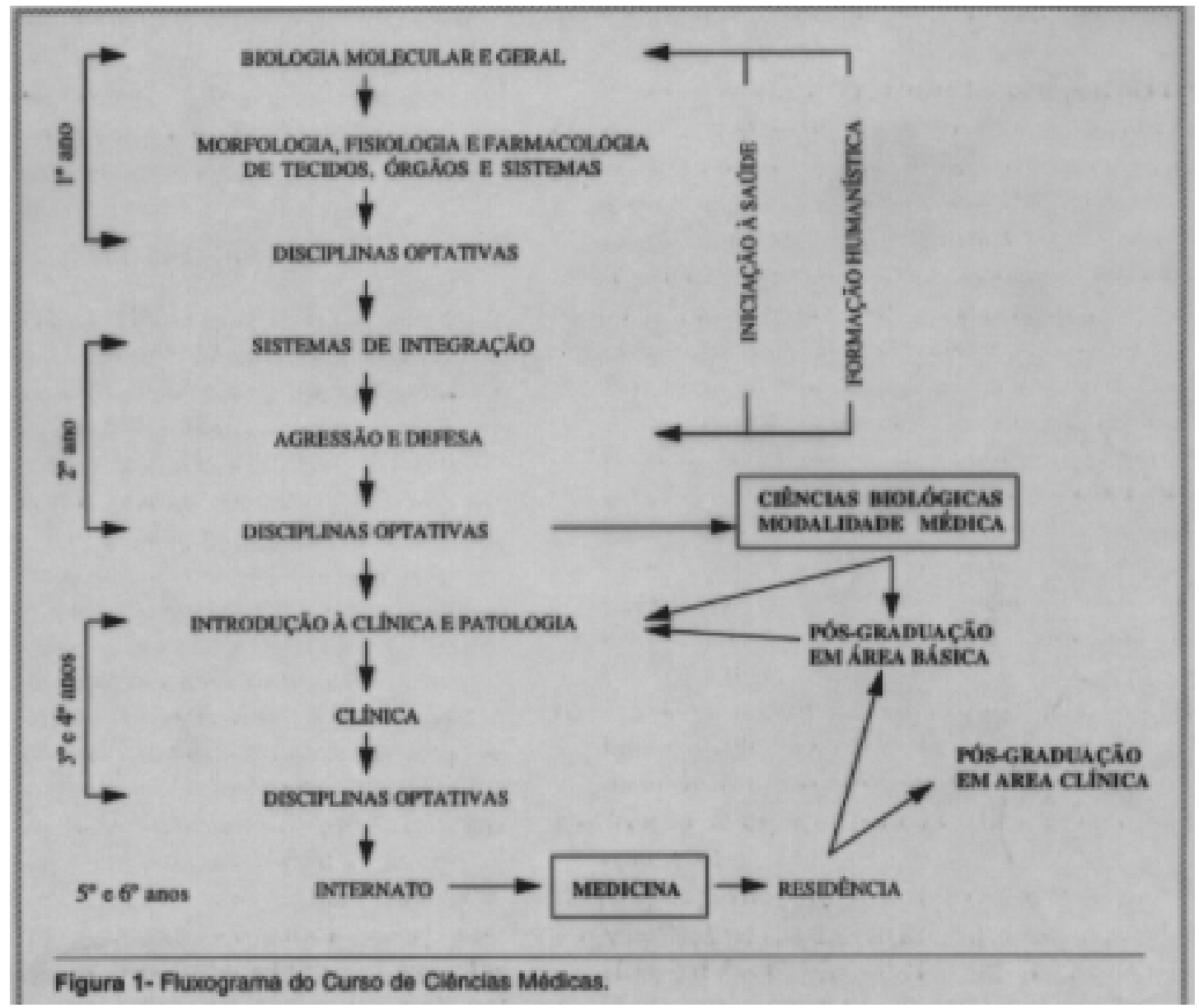


O anteprojeto dividia o Ciclo Básico em duas fases: a primeira, centrada no estudo do organismo normal, incluindo aspectos de Biologia Molecular e Geral (Figura 2). Morfologia. Fisiologia e Farmacologia de tecidos, órgãos e sistemas (Figura 3), e sistemas de integração (Figura 4); e a segunda, centrada nas bases gerais para compreensão de doenças, incluída em uma única disciplina, denominada Agressão e
Defesa (Figura 5). O anteprojeto previa, ainda, a criação da disciplina de Iniciação à Saúde, objetivando contato mais precoce do aluno com a Rede de Saúde, a disciplina de Formação Humanística do Saber Médico (dividida em Princípios de Ética, Filosofia da Ciência, História da Medicina e Ciências Sociais Aplicadas à Saúde) e a disciplina de Tecnologia de DNA Recombinante, além de espaços para disciplinas optativas.

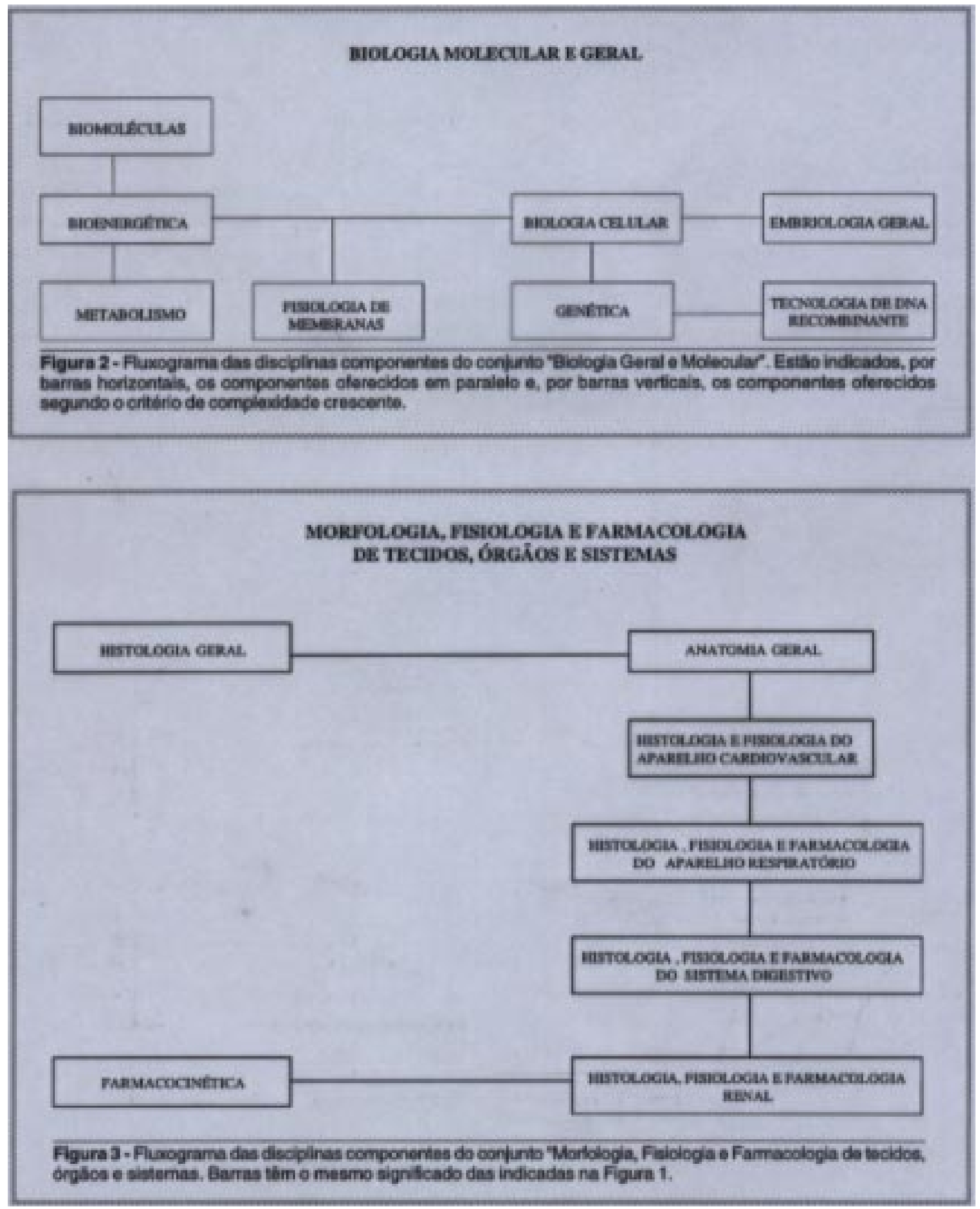




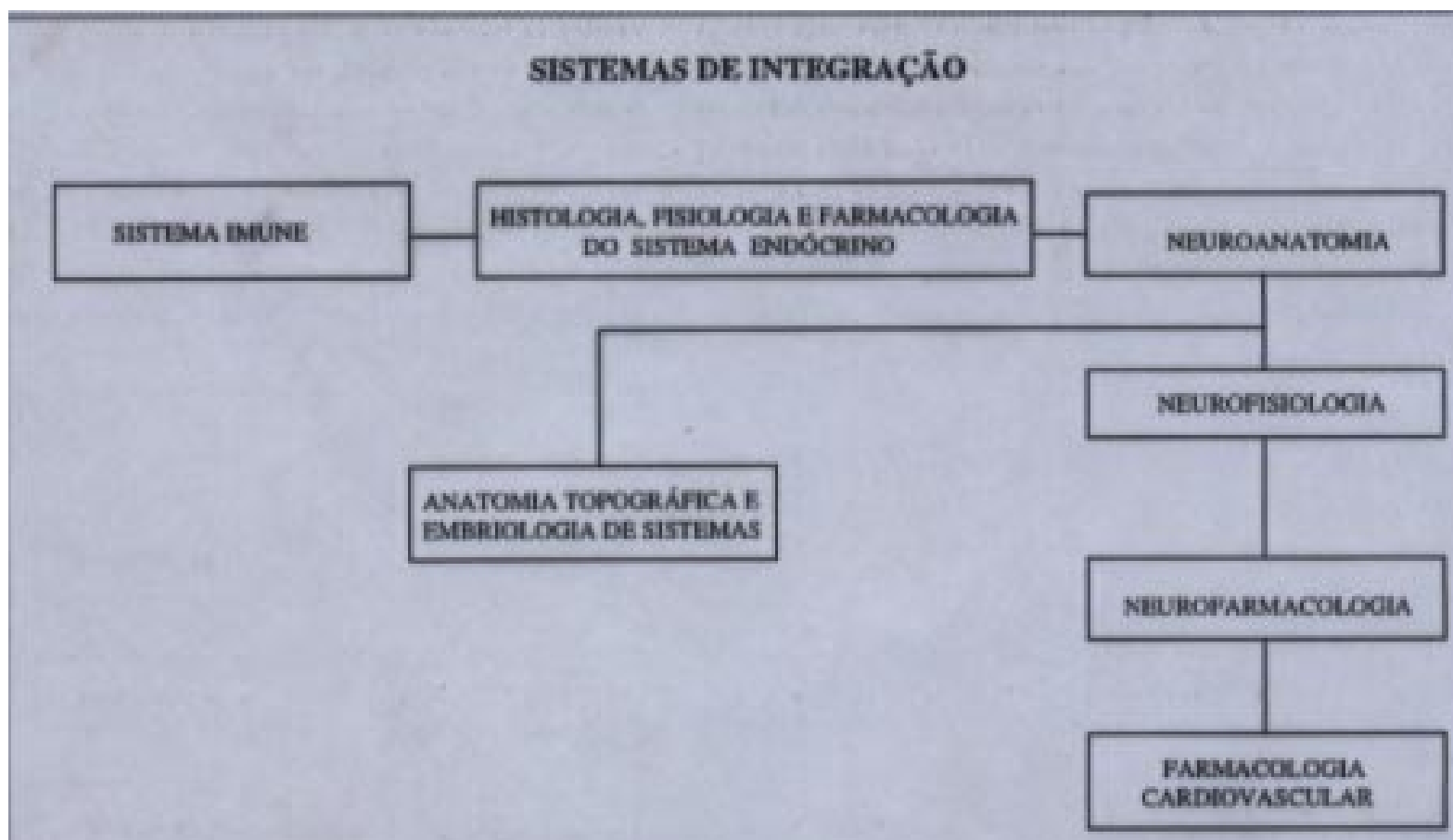

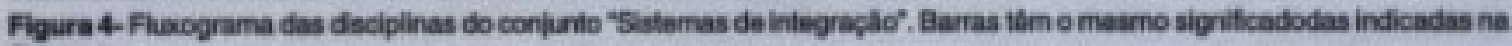
Figura 1.

\section{AGRESSÃo E DEFESA}

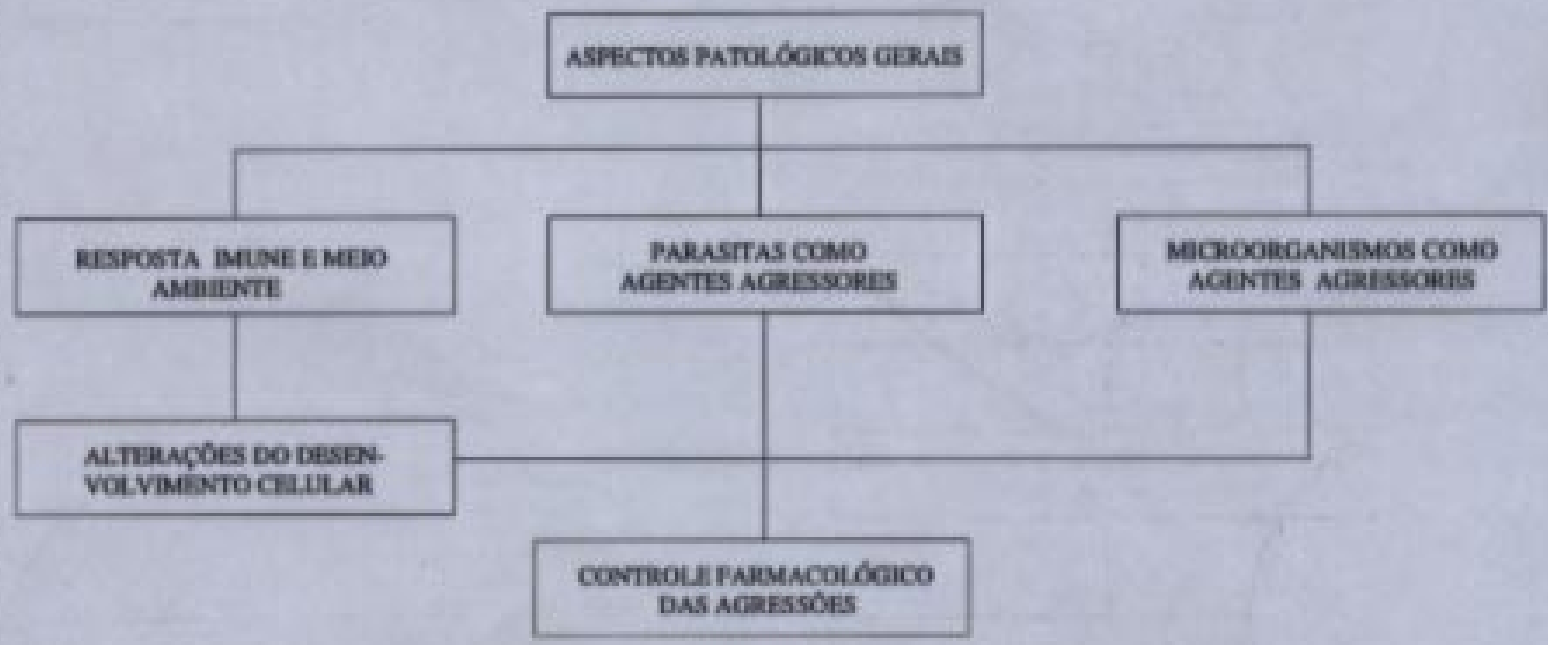

Figura 5 - Fluwograma das disciplinas componentes do conâuto "Agresslo e defesa". Barras têm o mesmo sipnificado des indicadas na Figura 1. 
O Ciclo Clínico foi também dividido em duas fases, uma pré-clínica (ou propedêutica), ocupando um semestre, e uma clínica, ocupando os 3 semestres subseqüentes. A fase pré-clínica (Figura 6) envolveria os cursos de Semiologia Geral, mantidos no molde clássico, Patologia, Psicologia e Psicologia Médica. No mesmo bloco, foram acrescentadas disciplinas novas como a Semiologia Pediátrica, a Semiologia Especializada (envolvendo Semiologia própria da Neurologia, Oftalmologia, Otorrinolaringologia, Ortopedia,
Nutrição, Ginecologia e Obstetrícia e Psiquiatria), Introdução ao Hospital, Diagnóstico por Imagens, e Bioética Médica. Na fase clínica (Figura 7), disciplinas então ministradas na Clínica Médica e repetidas na Cirurgia foram integradas em disciplinas conjuntas. Idêntica solução foi proposta, por exemplo, para se integrar a Neurologia com a Neurocirurgia. As demais disciplinas do Ciclo Clínico foram, inicialmente, apenas articuladas na estrutura curricular.

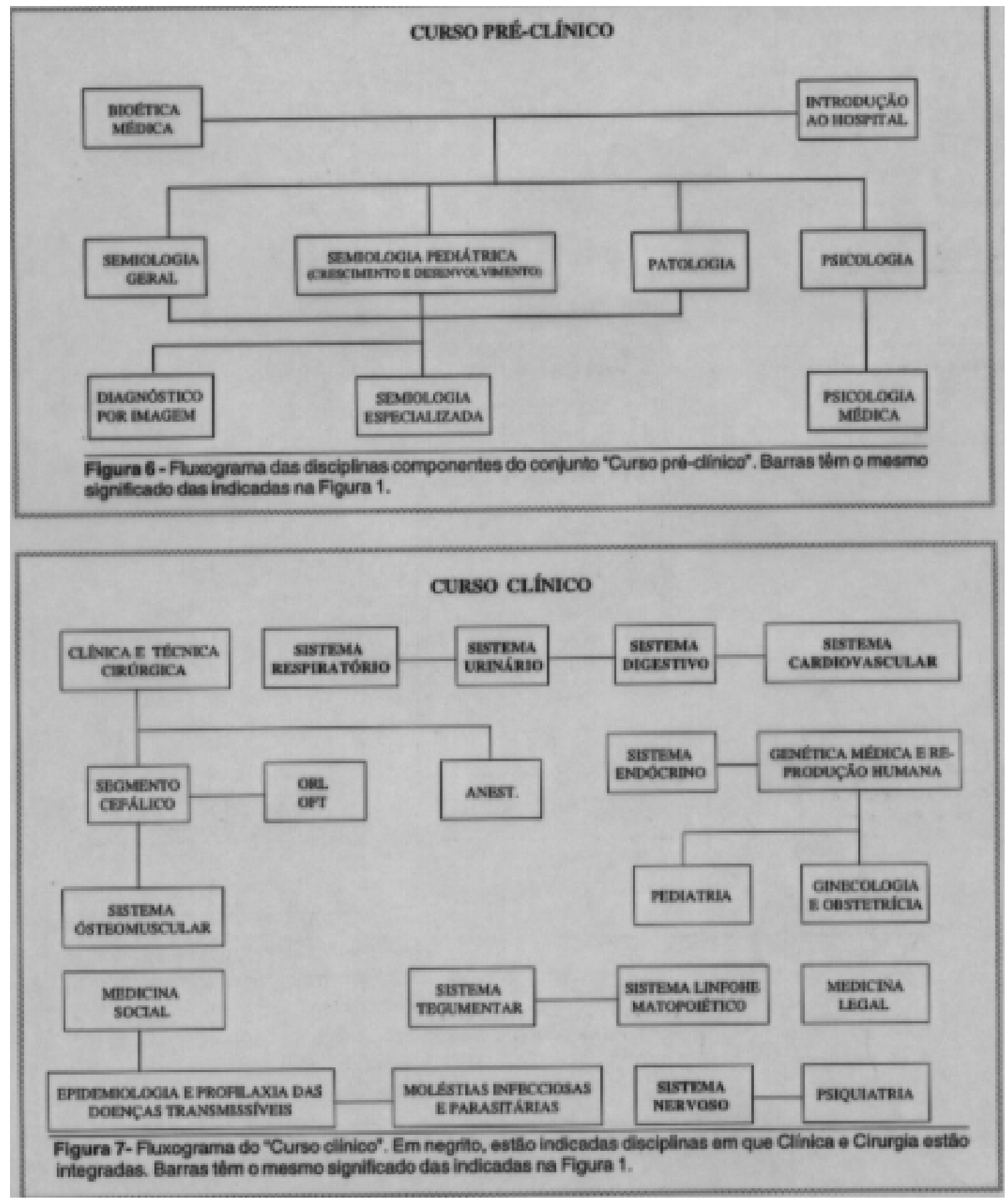




\section{CARACTERÍSTICAS DO ANTEPROJETO}

Foram identificadas, no referido anteprojeto, diversas características consideradas inovadoras, quando comparadas com as da estrutura até então vi gente (Tabela I). Na ocasião, solicitou-se aos participantes o exame do anteprojeto quanto a:

a- adequação do conteúdo das diversas disciplinas aos

objetivos terminais da FMRPUSP (Tabela II), aprovados em 27/03/87 ${ }^{8}$;

b- adequação dos assuntos ministrados ao critério de complexidade crescente;

c- adequação da articulação das disciplinas apresentadas no anteprojeto.

Os participantes do Seminário tiveram dificuldades em responder especificamente aos citados que sitos, mas apresentaram conclusões extremamente úteis ao processo, diversas delas efetivamente incorporadas aos objetivos da CG durante a implantação da nova estrutura. A síntese sumarizadado Seminário continha:
1 - sugestão de definição de coordenadores de disciplinas;

2 - avaliação continuada do ensino do novo curso;

3 - avaliação dos alunos formados tanto na antiga quanto na nova estrutura curricular;

4 - busca de estratégias que favoreçam as relações interpessoais, em especial a relação professor-aluno. Finalmente, em 15/05/92, o anteprojeto foi aprovado, por unanimidade, pela Congregação da FMRPUSP $^{9} \mathrm{e}$ a nova estrutura curricular, iniciada com a 42 $2^{\mathrm{a}}$ turma, ingressante em 1993.

Passados 4 anos de implantação da nova estrutura várias foram as providências tomadas para garantir as premissas da reestruturação, destacando-se: a - Implantação de processo de avaliação continuada das disciplinas, executada pelos estudantes, e seus resultados discutidos em reunião com docentes dela participantes, permitindo ajustes da grade curricular, alterações de carga horária, ou mesmo modi-

Tabela I - Características inovadoras do projeto

1- Flexibilização do curso de graduação permitindo ao aluno optar pelo bacharelato em Medicina, Ciências Biológicas-Modalidade Médica, ou em ambas.

2- Adequação das disciplinas às atuais tendências de multidisciplinaridade.

3- Introdução de conjunto de disciplinas que proporciona ao aluno a interpretação de fenômenos fisiopatológicos à luz da Biologia Molecular.

4- Articulação das disciplinas segundo critério de complexidade crescente, evoluindo da Biologia Celular até o funcionamento de sistemas.

5- Articulação das disciplinas Farmacologia, Genética, Imunologia, Parasitologia, Microbiologia e Patologia, visando o aprendizado integrado dos mecanismos básicos de agressão e defesa orgânica.

6- Ampliação da disciplina de Semiologia, integrando-a com tópicos de Semiologia Especializada.

7- Articulação das disciplinas clínicas, permitindo ensino integrado de especialidades.

8- Criação de espaço para internato optativo.

9- Criação de espaços para desenvolvimento de disciplinas optativas.

10- Criação das unidades de ensino Fundamentos Humanísticos do Saber Médico e Iniciação à Saúde.

11- Criação de Centro de Tecnologia Educacional, favorecendo a auto-instrução.

12- Criação de condições para a contínua avaliação do curso e dos seus egressos.

Tabela II - Objetivos educacionais da Faculdade de Medicina de Ribeirão Preto da USP

I - Propiciar condições para que o graduando possa ter sólida formação profissional, científica, humanística e uma visão global do sistema de saúde do país.

II - Propiciar condições para que o estudante possa ter diversidade de opções para sua formação profissional.

III - Proporcionar condições que auxiliem os alunos a desenvolver atitudes ativas, o hábito da reflexão, o auto-aprendizado, o espírito crítico, o compromisso ético e o trabalho em equipe. 
ficações de conteúdo. Em várias disciplinas, essa providência favoreceu real ou maior integração entre docentes de diferentes departamentos da Unidade.

b - Processo de avaliação do graduando em Medicina, iniciado com a formação de uma subcomissão sob comando de membros da CG, passando por etapa de adequação de docentes a mecanismos de avaliação até à efetiva aplicação dos mesmos ${ }^{10}$.

Sob o ponto de vista de recursos físicos, a FMRPUSP investiu na otimização dos espaços disponíveis para ensino, reformando e climatizando anfiteatros e dispondo-os de recursos audiovisuais e sonorização, modernos e eficientes. Além disso, investiu na instalação de Centro de Tecnologia Educacional, no qual estão à disposição modernos recursos de informática e vídeos que incentivam a auto-instrução do aluno.

\section{AVANÇOS OBTIDOS}

Dentre os avanços obtidos, destaca-se a boa receptividade das disciplinas optativas entre alunos e docentes. Criadas com a intenção de aproximar o estudante do trabalho diário do docente no laboratório ou, alternativamente, aprofundar conhecimentos em assunto abordado de modo mais genérico, no curso, aumentaram, significativamente, o número de estudantes interessados em programa de Iniciação Científica, usufruindo, assim, da inegável vocação para a pesquisa historicamente desenvolvida na FMRPUSP.

Outro avanço importante foi obter concordância do Departamento de Patologia para se proceder à integração de importante fração do conteúdo de Patologia com os das disciplinas do setor clínico. O conteúdo de Patologia Geral passou a ser oferecido na disciplina de Agressão e Defesa, ainda no Ciclo Básico; na fase pré-clínica o conteúdo de Patologia referente aos sistemas cardiovascular, respiratório, digestivo, renal e endócrino é oferecido em paralelo aos cursos de Semiologia e, na fase clínica, o Departamento de Patologia oferece conteúdos de Patologia Pediátrica, Ginecológica, Obstétrica e de Neuropatologia, integrados com as respectivas disciplinas clínicas.

A disciplina de Iniciação à Saúde também foi bem recebida pelo corpo discente e, a despeito de eventuais correções de conteúdo a serem ainda discutidos, tem atingido seu objetivo. A disciplina de Formação Humanística do Saber Médico encontra ainda resistência do corpo discente quanto a sua finalidade dentro de um Curso de Medicina. No entanto, tem sido inegável o progresso obtido entre os alunos quanto à postura ética esperada dos mesmos, principalmente quanto às suas obrigações no processo de reestruturação curricular.

\section{DIFICULDADES ENCONTRADAS}

Dentre as dificuldades encontradas para a implantação da nova estrutura curricular, dois aspectos devem ser considerados. Sob o ponto de vista de dificuldades técnicas, é necessário salientar que a CG, exceto em número desprezível de casos, sempre encontrou docentes dispostos a cooperar. Críticas específicas ao processo nunca foram oficialmente encaminhadas à CG. Sob o ponto de vista de conteúdo, entretanto, a Comissão de Graduação não tem obtido de todos os departamentos a colaboração indispensável para que a reestruturação resulte numa grade curricular menos sobrecarregada, aspecto em que a FMRPUSP não difere de escolas médicas do primeiro mundo ${ }^{11,12}$. De um modo geral, as principais dificuldades encontradas sob este aspecto podem ser assim resumidas:

\section{1- Excessiva carga horária destinada a aulas teóricas}

O padrão vigente na FMRPUSP segue o modelo clássico de ensino centrado no professor. Os concursos para ingresso de novos professores e mesmo os concursos para progresso na carreira docente obrigam o candidato à apresentação formal de uma aula teórica. A maioria das disciplinas não dispensam aulas teóricas formais, muitas delas excessivamente longas. Inserem-se, nestes casos, até disciplinas que dispõem de livro-texto completo e adequado aos objetivos do curso ou, pior ainda, disciplinas de cunho estritamente prático. Há muito se alertou que aulas teóricas não são eficientes para o aprendizado, pois a assimilação de informações diminui progressivamente, após 15 minutos de apresentação, e é praticamente nula, após 30 minutos $^{13}$. Na FMRPUSP, as aulas teóricas raramente duram menos que uma hora e freqüentemente se estendem por até quatro horas. Nem sempre as aulas teóricas são preparadas com o intuito de esclarecer um conceito ou facilitar ao aluno a compreensão de um fenômeno biológico. Na maioria dos casos, prestam apenas para que o aluno tenha um roteiro do conteúdo a ser estudado. Finalmente, é conhecido o fato de que conteúdos ministrados nestas condições são rapidamente esquecidos pelo aluno ${ }^{14}$. A Literatura tem registrado alternativas para o desenvolvimento do cur- 
rículo médico que incluem o ensino centrado 110 estudante, o ensino baseado em problemas e o ensino baseado na comunidade, utilizadas, com sucesso, em diversas escolas médicas do Hemisfério Norte ${ }^{15}$. As dificuldades para a implantação de modelos alternativos de ensino incluem a rejeição docente a um modo nãoconvencional de ensino e ao próprio tempo que deverá ser despendido para adequá-lo ao novo modelo. Além disso, modelos centrados no estudante aumentam a responsabilidade discente em seu próprio aprendizado. O ensino pré-universitário, no entanto, raramente oferece à Universidade alunos preparados para uma postura mais ativa. A despeito destas dificuldades, a CG, com o apoio irrestrito da FMRPUSP, tem incentivado a participação e treinamento de docentes interessados nesses novos modelos de ensino médico, assim como tem viabilizado a vinda de professores do exterior para ministrar cursos sobre o assunto, no recinto da FMRPUSP. Com relação ao internato de $5^{\circ}$ ano, a ser desenvolvido na nova estrutura curricular, a partir de 1997, a CG optou pelo incentivo da participação docente no modelo de ensino centrado na comunidade, assunto ainda em fase de discussão junto aos departamentos clínicos da Faculdade.

\section{2 - Sobrecarga de informações}

Este defeito da estrutura curricular está presente na maioria, senão em todas as escolas médicas. O currículo médico é, normalmente, carregado de informações factuais, freqüientemente, de pouca relevância clínica, tornando os estudantes de Medicina meros consumidores passivos de informações, sem estímulo à criatividade e à curiosidade Mesmo na nova estrutura curricular, é possível ${ }^{12}$. identificar que o conteúdo de diversas disciplinas, em especial as que ainda não foram integradas, é organizado e ensinado do mesmo modo como sempre o foram. Ainda que todos os coordenadores de disciplinas reconheçam que a sobrecarga existe, são unânimes em considerar que ela decorre do excesso de informações em disciplinas alheias. Outra motivação que colabora na sobrecarga do programa é a apresentação de aulas apenas como tentativa isolada de aumentar o interesse dos estudantes no campo da especialidade do docente, o que nem sempre se enquadra nos objetivos terminais da escola. As disciplinas optativas, neste aspecto, representam alternativa para os docentes desenvolverem com maior profundidade o assunto de sua preferência. A despeito do sucesso destas disciplinas, como comentado acima, nem todos os docentes, até o momento, apresentaram proposta de disciplina optativa.

\section{3 - Ausência de mecanismo de incentivo às ativi- dades de ensino de graduação}

Talvez seja este o maior obstáculo às mais efetivas e objetivas mudanças curriculares na FMRPUSP. Sob o ponto de vista salarial, gastar mais ou menos tempo com atividades de ensino de graduação não significa obter tratamento diferente por parte da Universidade. Para o progresso na carreira universitária, dáse pouco valor à participação do docente em ensino de graduação e enfatiza-se a produção científica e a dedicação ao ensino de pós-graduação. Neste aspecto, foi historicamente progressiva a preocupação da FMRPUSP com o ensino em nível de pós-graduação. No setor clínico da Faculdade este quadro é agravado pela necessidade que muitos docentes têm de aumentar seus rendimentos com atividades remuneradas de plantão na Unidade de Emergência e de assistência a pacientes particulares. Claro está que gastar tempo com o ensino de graduação reduz o tempo disponível para as atividades que garantem ganhos salariais mais dignos e/ou maior sucesso na carreira. Possivelmente sejam estes, também, os motivos da preferência por aulas teóricas, mesmo no Ciclo Clínico, urna vez que aulas em ambulatórios ou em enfermarias requerem a participação de um número maior de docente por período.

A reestruturação curricular da FMRPUSP, no ponto em que está, exige mais do que o simples rearranjo das disciplinas clássicas do currículo médico. Como considerado por Robert Watson, chefe do setor de Educação de Graduação do National Science Foundation, nos Estados Unidos (citado na ref. 16), alterações curriculares precisam começar no coração e mente dos indivíduos membros de uma Faculdade. É imperativo que cada docente, ao invés da visão voltada aos seus próprios interesses, preocupe-se com a sua quota de participação dentro do objetivo maior da Faculdade, o de formar médicos para servirem à comunidade. A instituição, por sua vez, deve obviar mudança estrutural que dê ao seu corpo docente incentivo à maior dedicação ao ensino de graduação. Fora destas providências, será excessivo o tempo gasto para se chegar a uma estrutura curricular adequada. A despeito da irrestrita colaboração docente conseguida pela Comissão de Graduação ao longo de 4 anos de processo de reestruturação curricular da FMRPUSP, depende-se, ainda, de mecanismo já mencionado na literatura sobre ensino médico, qual seja, "executamse as alterações possíveis e, enquanto isso, aguardase que várias pessoas façam a mesma coisa" ( $S$. Barkanic, citado na ref. 16). 
PRADO WA. Development and implantation of the new curricular structure in the School of Medicina of Ribeirão Preto: difficulties and advances. Medicina, Ribeirão Preto, 29:373-382, oct.Idec.1996.

ABSTRACT: Since 1993, the Medical School of Ribeirão Preto of the University of São Paulo is implanting the curricular structure of its new undergraduate course, named Course of Medical Sciences. This course allows students to graduate in Medicine, Biomedical Sciences, or both. In addition to such flexibility, the course is divided in three phases: basic, clinic and internship, lasting two years each. Traditional disciplines were integrated into new disciplines or articulated on the basis of increased complexity, avoiding curricular repetition. New disciplines were added to allow early contact of the students with the health system and improve their ethic and humanistic background. New disciplines on topics of specialized semiology were also introduced. Other advances include facilities to stimulate students in self-learning methods and space for optional disciplines. Main difficulties to develop the new curriculum include the resistance of teachers to minimize the emphasis on formal lectures, the information overload, and the lack of institutional reward mechanisms for teachers involved with undergraduate medical education.

UNITERMS: Education, Medical. Faculty, Medical Education, Medical, Undergraduate.

\section{REFERÊNCIAS BIBLIOGRÁFICAS}

1 - VAN DER VLEUTEN C. Improving medical education. BMJ 306: 284-285,1993.

2 - FIGUEIREDO FC \& RODRIGUES CRC. Estratégias para a reformulação da estrutura curricular na Faculdade de Medicina de Ribeirão Preto na última década e estágio atual do processo. R Bras Educ Med 14: 20-23, 1990.

3- COMISSÃO DE GRADUAÇÃO. FACULDADE DE MEDICINA DE RIBEIRÃO PRETO. Parecer CG 10/90. FMRP, Ribeirão Preto, 1990.

4- FACULDADE DE MEDICINA DE RIBEIRÃO PRETO. Processo 92.1.321.17.0, Plano Diretor. FMRP, Ribeirão Preto, s.d.

5- COMISSÃO DE GRADUAÇÃO. FACULDADE DE MEDICINA DE RIBEIRÃO PRETO. Atas das Reuniões, 1991. FMRP, Ribeirão Preto, s.d.

6- CONGREGAÇÃO DAFACULDADE DE MEDICINA DE RIBEIRÃO PRETO. Atas das reuniões, 1991. FMRP, Ribeirão Preto, s.d.

7- CONGREGAÇÃO DAFACULDADE DE MEDICINA DE RIBEIRÃO PRETO. Atas das reuniões, 1995. FMRP, Ribeirão Preto, s.d.

8- CONGREGAÇÃO DAFACULDADE DE MEDICINA DE RIBEIRÃO PRETO. Atas das reuniões, 1987. FMRP, Ribeirão Preto, s.d.
9- CONGREGAÇÃO DAFACULDADE DE MEDICINADE RIBEIRÃO PRETO. Atas das reuniões, 1992. FMRP, Ribeirão Preto, s.d.

10 - TRONCON LEA et al. Avaliação terminal de competências dos graduandos em Medicina: relato da experiência inicial da Faculdade de Medicina de Ribeirão Preto, Faculdade de Medicina de Ribeirão Preto, Ribeirão Preto, 1996.

11 - ANDERSON J \& GRAHAM A. A problem in medical education: is there na information overload? Med Educ 14: 4-7, 1980.

12- LOWRY 5. Curriculum design. BMJ 305: 1409-1411, 1992.

13- MILLER M. Changing medical education in Western Europe. Med Educ 12 (Suppl 2), 1978.

14-GENERAL MEDICAL COUNCIL. Undergraduate medical education. Tlie need for change. GMC, London, 1991.

15 - HARDEN RM et ai. Some educational strategies in curriculum deveiopment: the spices model. Med Educ 18:284-297, 1984.

16- SERVIC RF. Assault on the lesson plan. Science 266: 856858, 1994.

Recebido para publicação em 23/10/96

Aprovado para publicação em 11/12/96 